\title{
Asian women's use of specialist Contraception, Sexual and Reproductive Health Services in Leicester, UK
}

\author{
Sharon Moses, Emeka Oloto
}

\begin{abstract}
Background There is evidence to suggest that Asian women in the UK have specific contraceptive and sexual health needs. It has been reported that Asian women may use less reliable contraceptive methods and that cultural influences can affect access to sexual health services. As part of a wider needs assessment project we compared Asian women's usage of our specialist Contraception, Sexual and Reproductive Health Services to that of nonAsian women.
\end{abstract}

Methods An anonymous questionnaire was offered to all service users between October and December 2007. Data were analysed separately for Asian and non-Asian women.

Results The response rate was low for Asian women with only $26 \%$ completing questionnaires. There were no significant differences between the groups for proportions of women attending for each contraceptive method. A smaller proportion of Asian women were using the service for contraception and a greater proportion were attending for other sexual health reasons compared to non-Asian women. Confidentiality, female staff and not wanting to see their general practitioner were stated more often as reasons for using our service by Asian women.

Conclusions The National Strategy for Sexual Health and HIV emphasises the need for services targeted at ethnic minorities. Asian women use our clinics for a variety of their sexual health needs. Our service is used by some in preference to general practice, which may reflect ease of access and the perceived confidentiality that a dedicated Contraception and Sexual Health Service offers. These preferences should be considered by primary care trusts when commissioning services.

Keywords Asian, contraception, ethnicity, service provision, sexual health

J Fam Plann Reprod Health Care 2010; 36(3): 137-140

(Accepted 11 February 2010)

\section{Introduction}

Leicester has an ethnically diverse population. Neighbourhood statistics from $2006^{1}$ identified that $60 \%$ of women aged 16-59 years in Leicester were white, $31 \%$ Asian and the remaining 9\% were of black, Chinese, mixed or other ethnic groups. Asian includes persons of Indian, Pakistani, Bangladeshi, other Asian descent and British Asian. A recent overview of research regarding sexual and reproductive health of Asians in the $\mathrm{UK}^{2}$ highlighted specific needs of this ethnic group and differences in contraceptive behaviour and access to sexual health services. From the review, ${ }^{2}$ Asian women generally appeared to be using less reliable methods of contraception and cultural factors influenced Asian women's access to various sexual health providers. The National Strategy for Sexual Health and HIV ${ }^{3}$ comments on inequalities in the UK for sexual health of black and minority ethnic groups and the need for targeted services.

Contraception, Sexual and Reproductive Health Services in Leicester, UK is a specialist level 3 provider (excluding HIV care). The central clinic at St Peter's Health Centre is located in Leicester city centre and offers provision and management of complications for all reversible contraception as well as vasectomy, counselling and referral for unplanned pregnancy, psychosexual counselling, and screening for sexually transmitted infections (STIs). There are also seven satellite clinics located elsewhere in Leicester city, Leicestershire and

Department of Contraception, Sexual \& Reproductive Health Services, University Hospitals of Leicester NHS Trust, Leicester, UK

Sharon Moses, MRCOG MFSRH, Consultant in Reproductive and Sexual Health

Emeka Oloto, FRCOG, FFSRH, Consultant in Sexual and Reproductive Health

Correspondence to: Dr Sharon Moses, St Patrick's Centre for Community Health, Frank Street, Highgate, Birmingham B12 OYA, UK. E-mail: sharon.moses@hobtpct.nhs.uk

\section{Key message points \\ - A greater proportion of Asian women were attending our specialist service for a non-contraceptive reason compared to non-Asian women. \\ - Confidentiality, female staff and not wanting to see their general practitioner were more frequent reasons given by Asian women for using the service, compared to non- Asian women. \\ - Primary care trusts should consider user preferences when commissioning contraception, sexual and reproductive health services.}

Rutland, which offer level 2 services. In order to improve our service we conducted a needs assessment project in 2007 to determine who was using our service; what for; reasons why; and customer preferences. In view of the high proportion of Asian women in Leicester it was deemed useful to conduct a subanalysis comparing the findings for Asian service users to non-Asian for our central level 3 clinic. The aim of this analysis was to ascertain any differences between the groups and identify specific needs in order to guide service improvement, development and commissioning.

\section{Methods}

An anonymous and voluntary needs assessment questionnaire was offered to service users attending all clinics for a 6-week period between October and December 2007. Questionnaires were double-sided with minimum free text to facilitate ease of response. Demographic factors of age and ethnic group were collected. Reasons for attending clinic were recorded and included both contraceptive and non-contraceptive indications. Contraceptive reasons included any visit relating to the currently available individual contraceptive methods. Further questions addressed reasons for using the service, incorporating preferences for not being seen in general practice. Views on ideal opening times and clinic types were requested. All users were asked if they were happy 
with the existing service and free text was available for comments.

The questionnaire was initially piloted within the department. Only an English language version was available, although interpreters used for consultation could assist with completion of the questionnaire. Data were collated on an Access ${ }^{\mathrm{TM}}$ database and analysed with Statistical Package for the Social Sciences (SPSS) ${ }^{\circledR}$ version 15 (SPSS Inc., Chicago, IL, USA). A Chi-square test with Yates correction and $t$-test (for comparison of means) were used for further statistical analysis. A $p$ value of less than 0.05 was considered significant. Data presented here represent questionnaires collected from our level 3 central clinic at St Peter's Health Centre only.

\section{Results}

A total of 585 questionnaires were collected from female service users (1442 female attendances during time period) giving a response rate of $40.6 \%$. Questionnaires were received from 143 Asian women and 442 non-Asian women, with respective response rates of $25.6 \%$ (143/559) and $50.1 \%$ (442/883). Table 1 shows the number of questionnaires completed by ethnic group.

The mean age of Asian women using the service was 27.9 [standard deviation (SD) 8.37, range 13-52] years, which was similar to the mean age of 26.9 (SD 8.88, range 15-56) years for non-Asian women. Of the Asian women who responded, $37.1 \%$ (53/143) were aged under 25 years with $16.1 \%$ (23/143) under 20 years. More non-Asian women were aged under 25 years [49.3\% (218/442)] and $23.8 \%(105 / 442)$ were aged under 20 years.

\section{Contraceptive reasons for service use}

A significantly greater proportion of non-Asian women were attending the service for contraceptive reasons $[79.4 \%(351 / 442)]$ compared to $67.1 \%(96 / 143)$ of Asian women, which is statistically significant $(p=0.004)$ by Chi-square test. Table 2 shows contraceptive reasons given for using the service by Asian and non-Asian women ('other' includes condoms, barrier methods, natural family planning and unsure of method). There were no significant differences between the two groups. Pills were the most popular method in both groups. The intrauterine device was the second most popular method for Asian women whereas the implant was second for non-Asian women. Only small proportions of women attended because of perceived contraceptive problems [3.1\% (3/96) Asian and 6.6\% (23/351) non-Asian].

\section{Non-contraceptive reasons for service use}

A significantly greater proportion of Asian women were attending for a non-contraceptive reason [41.3\% (59/143)]

Table 1 Number of female St Peter's Clinic users completing questionnaires by ethnic group

\begin{tabular}{lcc}
\hline Ethnic group & $\begin{array}{l}\text { Service } \\
\text { users }(\boldsymbol{n})\end{array}$ & $\begin{array}{l}\text { Percentage } \\
(\%)\end{array}$ \\
\hline Asian Women $(n=143)$ & & \\
$\quad$ Indian & 113 & 19.3 \\
Pakistani & 18 & 3.1 \\
Bangladeshi & 4 & 0.7 \\
Other Asian & 8 & 1.4 \\
Non-Asian women $(n=442)$ & & \\
White & 309 & 52.8 \\
Mixed & 43 & 7.4 \\
Black or black British & 70 & 11.9 \\
Chinese or other & 16 & 2.7 \\
Not given & 4 & 0.7 \\
Total & 585 & 100.0 \\
\hline
\end{tabular}

Table 2 Comparison of contraceptive reasons for using St Peter's Clinic between Asian and non-Asian womena

\begin{tabular}{|c|c|c|c|c|c|}
\hline \multirow[t]{2}{*}{$\begin{array}{l}\text { Contraceptive } \\
\text { method }\end{array}$} & \multicolumn{2}{|c|}{$\begin{array}{l}\text { Asian women } \\
(n=96)\end{array}$} & \multicolumn{2}{|c|}{$\begin{array}{l}\text { Non-Asian women } \\
(n=351)\end{array}$} & \multirow[t]{2}{*}{$p$} \\
\hline & $n$ & $\%$ & $n$ & $\%$ & \\
\hline Intrauterine system & 13 & 13.5 & 43 & 12.3 & 0.87 \\
\hline Intrauterine device & 17 & 17.7 & 52 & 14.8 & 0.59 \\
\hline Subdermal implant & 15 & 15.6 & 77 & 21.9 & 0.22 \\
\hline Injection & 7 & 7.3 & 30 & 8.5 & 0.85 \\
\hline Pills & 26 & 27.1 & 95 & 27.1 & 0.99 \\
\hline Sterilisation & 0 & 0.0 & 1 & 0.3 & 0.60 \\
\hline Emergency hormonal & 10 & 10.4 & 29 & 8.3 & 0.65 \\
\hline Other & 10 & 10.4 & 28 & 8.0 & 0.58 \\
\hline
\end{tabular}

aMore than one contraceptive method could be given.

compared to $26.2 \%(116 / 442)$ for non-Asian women ( $p=$ $0.001)$. Non-contraceptive reasons for visiting the service are given in Table 3 . There were no significant differences between the groups as regards non-contraceptive reasons for attending the service. Only $9.1 \%$ (13/143) of Asian women and $5.9 \%(26 / 442)$ of non-Asian women stated that they were attending for both contraceptive and noncontraceptive reasons.

\section{General reasons for service use}

All women were also asked for reasons why they used our service and these are shown in Table 4. A significantly larger proportion of Asian women described confidentiality, female staff and not wanting to see their general practitioner (GP) as reasons for using the service. Walk-in clinics were a popular reason for both groups. Services not being available with their GP or being advised to attend by their GP were the other most popular reasons for service use by non-Asian women.

Generally, satisfaction with the service was similar, with $82.5 \%(118 / 143)$ of Asian women and $78.5 \%$ (347/442) of non-Asian women being happy with the current service. Morning opening times were desired by $54.5 \%(78 / 143)$ of Asian women and $60.4 \%$ (267/442) of non-Asian women. A significantly greater proportion of non-Asian women wanted afternoon opening [63.6\% (281/442)] compared to $44.8 \%$ (64/143) of Asian women ( $p=0.001$ by Chi-square test). Preferences for evening openings were similar: $46.2 \%(66 / 143)$ of Asian women and $53.8 \%(238 / 442)$ of non-Asian women. Both groups of women preferred booked appointments compared to walkin clinics. Booked appointments were preferred by $47.4 \%$ (72/152) of Asian women and 52\% (451/868) of non-Asian women. Walk-in clinics were preferred by $33.6 \%(51 / 152)$ of Asian women and 33.8\% (293/868) of non-Asian women.

Table 3 Comparison of non-contraceptive reasons for using St Peter's Clinic between Asian and non-Asian womena

\begin{tabular}{|c|c|c|c|c|c|}
\hline \multirow[t]{2}{*}{$\begin{array}{l}\text { Contraceptive } \\
\text { method }\end{array}$} & \multicolumn{2}{|c|}{$\begin{array}{l}\text { Asian women } \\
(n=59)\end{array}$} & \multicolumn{2}{|c|}{$\begin{array}{l}\text { Non-Asian } \\
\text { women }(n=116)\end{array}$} & \multirow[t]{2}{*}{$p$} \\
\hline & $n$ & $\%$ & $n$ & $\%$ & \\
\hline Pregnancy test & 27 & 45.8 & 35 & 30.2 & 0.06 \\
\hline Smear & 13 & 22.0 & 17 & 14.7 & 0.31 \\
\hline Infection tests & 5 & 8.5 & 15 & 12.9 & 0.53 \\
\hline Unplanned pregnancy & 15 & 25.4 & 43 & 37.1 & 0.17 \\
\hline Psychosexual & 0 & 0.0 & 3 & 2.6 & 0.53 \\
\hline
\end{tabular}

aMore than one non-contraceptive reason could be given. 
Table 4 Comparison of reasons for using St Peter's Clinic between Asian and non-Asian women

\begin{tabular}{|c|c|c|c|c|c|}
\hline \multirow[t]{2}{*}{ Reason for using service } & \multicolumn{2}{|c|}{$\begin{array}{l}\text { Asian women } \\
(n=143)\end{array}$} & \multicolumn{2}{|c|}{$\begin{array}{l}\text { Non-Asian women } \\
(n=442)\end{array}$} & \multirow[t]{2}{*}{$p^{\mathrm{a}}$} \\
\hline & $n$ & $\%$ & $n$ & $\%$ & \\
\hline Convenience & 35 & 24.5 & 103 & 23.3 & 0.86 \\
\hline Live/work nearby & 29 & 20.3 & 65 & 14.7 & 0.15 \\
\hline Confidentiality & 51 & 35.7 & 92 & 20.8 & 0.0005 \\
\hline Friendly staff & 37 & 25.9 & 107 & 24.2 & 0.77 \\
\hline Free prescriptions & 18 & 12.6 & 54 & 12.2 & 0.91 \\
\hline Walk-in clinics & 49 & 34.3 & 134 & 30.3 & 0.43 \\
\hline Young persons clinic & 16 & 11.2 & 64 & 14.5 & 0.39 \\
\hline Easy to get appointment & 20 & 14.0 & 47 & 10.6 & 0.35 \\
\hline Service not available elsewhere & 11 & 7.7 & 38 & 8.6 & 0.92 \\
\hline Told to come by GP & 27 & 18.9 & 116 & 26.2 & 0.09 \\
\hline GP does not offer service & 37 & 25.9 & 134 & 30.3 & 0.36 \\
\hline Don't want to see GP & 46 & 32.2 & 82 & 18.6 & 0.0009 \\
\hline Don't have a GP & 5 & 3.5 & 34 & 7.7 & 0.12 \\
\hline Inconvenient GP appointment times & 23 & 16.1 & 88 & 19.9 & 0.37 \\
\hline Don't know if GP offers service & 13 & 9.1 & 32 & 7.2 & 0.59 \\
\hline
\end{tabular}

aSignificant values are given in bold type. GP, general practitioner.

\section{Discussion}

The response rate from our needs assessment project is average. The poor response rate from Asian women is disappointing but highlights some limitations of our process, which may have missed women for whom language or other difficulties were a barrier to completing the voluntary questionnaire. Subanalysis was limited to the central clinic as the satellite clinics have a predominantly white British population. Information regarding marital or professional status, which has previously been shown ${ }^{4}$ to influence contraceptive use and behaviour, were not collected which may further limit findings. The data obtained, however, do not represent original research but instead are an attempt to guide and hopefully improve service provision.

Our service offers dedicated young person's clinics. Although the mean age of women who answered questionnaires was similar, a greater proportion of nonAsian women were aged under 25 years. Evidence from the literature ${ }^{5}$ suggests that young Asians are less likely than their peers to report experience of sex and have relatively poor sexual health knowledge. Whether the smaller proportion of Asian women aged under 25 years using our service is due to delayed age of sexual activity or not accessing services is unclear and would be a useful area for future local research. It may be that our service needs clearer signposting and targeted services for Asian young people who are sexually active.

The majority of service users were attending for contraceptive reasons. As a specialist contraceptive provider it is not surprising that long-acting reversible contraceptive (LARC) methods were popular, with $54.2 \%$ (52/96) of Asian women and 57.5\% (202/351) of nonAsian women attending for LARC-related reasons. The trend from the results suggested that the IUD was more popular amongst Asian women in line with previous research, ${ }^{2}$ however hormonal LARC were also frequently requested. The contraceptive efficacy and cost effectiveness of LARC methods is well established and it is reassuring to know that these methods are being accessed from our service by both Asian and non-Asian women.

There is conflicting evidence on whether Asians prefer to access general practice for sexual health needs. ${ }^{2}$ From our data it appeared that Asian women were using our service for a variety of sexual health needs and were more likely to be attending for a non-contraceptive reason than non-Asian women. This may link into their reasons for using the service. Asian women were significantly more likely to state confidentiality, female staff and not wanting to see their GP as reasons for attending our service compared to non-Asian women. Greater proportions of non-Asian women stated being told to attend by their GP and service not available at their general practice as reasons, suggesting that the GP was their first port of call rather than a dedicated contraception and sexual health service. The issue of why women did not want to see their GP was not explored further by the questionnaire, however it does raise important issues for commissioning. Off the back of the National Strategy for Sexual Health and HIV ${ }^{3}$ and the LARC Guideline, ${ }^{6}$ GPs are and will be providing more enhanced contraceptive and sexual health services. It is important to remember that GPs and their settings may not fulfil the needs and requirements of all clients.

Overall satisfaction with the service was good for both groups. Morning appointments were preferred by Asian women compared to afternoon appointments for non-Asian women but the differences were small. Booked appointments were preferred by both groups despite walkin clinics being a popular reason for service use. Socioeconomic factors may influence predilection for opening times and clinic types but these data was not collected and it is an area for wider research. The variation in preferences for opening times and appointment types underpins the need for having a flexible service in an effort to try and fit the needs of the local population.

The subanalysis of our needs assessment has revealed some interesting differences between Asian and non-Asian respondents regarding use of our specialist service. We are reassured by the good satisfaction rates and also the high interest in LARC methods across both groups but we are not complacent. Our data reinforce the belief that the confidentiality and range of services within a communitybased sexual health service provide a valuable accessible health resource for women who may not feel comfortable and/or find it convenient to see their GP. These preferences should be considered when services are being commissioned by primary care trusts.

Statements on funding and competing interests Funding None identified. Competing interests None identified. 
References

1 Office for National Statistics (ONS). Neighbourhood Statistics. 2006. http://www.neighbourhood.statistics.gov.uk/ dissemination/LeadTableView.do $\mathrm{a}=7 \& b=276827 \& \mathrm{c}=$ leicester $\& d=13 \& e=13 \& g=394575 \& \mathrm{i}=1001 \times 1003 \times 1004 \& m=0 \& r=1 \& s=1$ 236551758032\&enc $=1$ \&dsFamilyld $=1811$ [Accessed 3 February 2010].

2 Griffiths C, Prost A, Graham H. Sexual and reproductive health of South Asians in the UK: an overview. J Fam Plann Reprod Health Care 2008; 34: 251-260.

3 Department of Health. The National Strategy for Sexual Health and HIV. London, UK: Department of Health, 2001.
4 Hennink M, Diamond I, Cooper P. Contraceptive use dynamics of Asian women in Britain. J Biosoc Sci 1999; 31: 537-554.

5 Testa A, Coleman L. Sexual Health Knowledge, Attitudes and Behaviours Among Black and Minority Ethnic Youth in London. A Summary of Findings. London, UK: Trust for the Study of Adolescence and Naz Project London, 2006.

6 National Institute for Health and Clinical Excellence (NICE). Long-Acting Reversible Contraception: The Effective and Appropriate Use of Long-Acting Reversible Contraception (Clinical Guidance 30). 2005. http://www.nice.org.uk/nice media/pdf/CG030fullguideline.pdf [Accessed 3 February 2010].

\section{"UR WLCM"}

\section{P C MacBerry}

"So, well, it's like, well book innit." Through my headphones I'm expecting to hear a university-educated voice ask me to "Please repeat this phrase", just like when trying to learn any new language. I've been forced to try this method in an attempt to understand what the 'yoof' of today are talking about. This way I can help them and also can satisfy the demands of the NHS's 'You're Welcome' strategy that wants us all to "improve our services and be more young people friendly".

There's no way I can do this unless I understand what on earth they are saying and, indeed, 'where they're coming from' - which I'm sure is usually straight from their bed, if their state of dress, general coiffure and vocal clarity is anything to go by. Which is why I'm now listening to an iPod ${ }^{T M}$ - I'd of course heard of these but had no idea what they actually were, or did - and to phrases my teenage god-daughter has kindly recorded, blue-toothed and podcasted to me, or so she says. I've no idea what any of this means either. I've acquired this iPod courtesy of registering with an online medical education site. Well, I didn't actually register; my neighbour's 9-year-old sorted that for me.

So we have to make health services more friendly and get in tune with the kids of today, do we? I'm struggling with this. Removing my tie and leaving my top shirt button undone has left me feeling rather exposed. In all the confusion I forgot my trouser belt the other day only to be greeted by whoops of laughter and cries of "Easi, Doc", "You looking buff, man. Serious" and "Appreciate" from the young people in the waiting room. Apparently my trousers clinging for dear life to my hips, exposing my undergarment elastic, had 'made it large' - I wasn't going to complain about that kind of compliment I thought. But honestly, I don't know how those lads manage to keep their trousers where they are, and whilst moving too, albeit in a way that adds epididymo-orchitis to the list of differentials. Extraordinary. I came close to more 'priceless' moments like this until I managed to find yet another use for a stretched condom.

Forget all this 'make them feel welcome and at ease' lark, what young people need is to smarten up, sit up straight, and speak clearly. A year or two in the military wouldn't go amiss. It would teach them some discipline and the skills of appropriate penetration, timely

J Fam Plann Reprod Health Care 2010; 36(3): 140

Blewtoufit Surgery, Wye Fytham, UK

P C MacBerry, MRCGP, General Practitioner withdrawal, and the importance of barrier protection. After all, there's a war on apparently, between two local gangs it would seem. Not the most dangerous by all accounts if their 'tags' are anything to go by: the 'Apples' and the 'Blackberries'. Obviously there's some serious rivalry and point-scoring going on here because it's becoming the norm for some of these youngsters to want their STI test results sent to their 'Blackberry'. I daren't ask which gang a person belongs to but I do hope that their request for this is a demonstration of some responsibility, making sure those they may have exposed to infection are alerted and contact traced. Of course, if they belong to the 'Apples' then this is only going to discharge further inflammation.

I do realise that coming to a clinic such as ours may be intimidating and embarrassing for some. So one step we took to make things easier was to place chlamydia tests in the ladies' and in the gents' with a 'Please take one' sign. Five minutes later they were all gone. We subsequently learned they were being sold on $\mathrm{eBay}^{\mathrm{TM}}$, where you can allegedly buy anything. Another innovation was to encourage young people to bring a friend along, for support and to help them feel more in control. Of course that doesn't always work either. I was pleased to reassure one young lady that her problem was thrush, and that it was easily treated. She understandably felt a little taken aback when I explained the treatment was a pessary. I had hoped that her friend would have been a help here, but no "He says you gotta put it up in you tube" was her response. My patient looked even more alarmed: "I don't want everyone to see what I'm doing!"'.

Since the trouser escapade had been so surprisingly positive I did try repositioning my comb-over so it flopped over one eye but it really didn't achieve the desired effect. It behaved like an elderly penis rather than a youthful one that springs about as you move. I couldn't see half of what was in front of me anyway, and I looked a right 'tweet' I think someone said.

Whilst this latest NHS strategy remains nonmandatory I'll continue to do what I've always done: to do my best for my younger patients with what knowledge and skills I have. As always, I'll offer them the widest choice of services but I'll still persevere with getting to grips with the barriers that come between us. OK, back to the 'Avatar Patient-Doctor Consultation Training Programme':

\footnotetext{
"Oi. You 'aving a LARC?"

"Fank you, Doc."

"UR WLCM."
} 